\title{
Brainwave Cloud Classroom Training Program in Elderly People
}

\author{
Worapol Pengsuwan \\ Brain Science and Engineering Innovation Research Unit \\ School of Anti-Aging and Regenerative Medicine \\ Mae Fah Luang University, Bangkok, Thailand \\ Email: wrp.psw@gmail.com
}

\author{
Shao-Chin Chang \\ Department of Physical Science and Technology \\ Yinchun University \\ Jiangxi, China \\ Email: william@alchemytech.com.tw
}

\author{
Sy-Ruen Huang \\ Chung Chou University of Science and Technology \\ Yuanlin City \\ Changhua County, Taiwan \\ Email: srhuang@dragon.ccut.edu.tw
}

\author{
Djohan \\ Graduate School of Indonesia Institute of the Arts \\ Indonesia Institute of the Arts \\ Yogyakarta, Indonesia \\ Email:djohan.djohan@yahoo.com
}

\author{
Phakkharawat Sittiprapaporn \\ Brain Science and Engineering Innovation Research Unit \\ School of Anti-Aging and Regenerative Medicine \\ Mae Fah Luang University, Bangkok, Thailand \\ Email:wichian.sit@mfu.ac.th
}

\begin{abstract}
The purpose of this study was to investigate the effect of using brainwave cloud classroom program on the brainwave's changes in elderly. The sample of this study were fourteen participants, which were four men and ten women, aged 61-84 years old. All participants were measured their brainwaves prior to the brainwave cloud classroom program training. During the training, should any participant could not proceed to the next session, he/she was measured their brainwaves again. They were allowed to break for fifteen to thirty minutes. Then, the second training was done and that participants were measured their brainwaves again. The result showed that delta, theta, alpha, and beta brainwaves were gradually decreased with no statistically significant while gamma brainwave did not change.
\end{abstract}

\section{Keywords-Brain; Brainwaves; Attention; Cloud Classroom}

\section{INTRODUCTION}

Brain is an organ that is easily affected by the physical changes [1]. Parts of the brain that control the activities have been defined by experts in the field of science of the nervous system. For instance, the top of the brain controls the limbs while the rear of the brain is responsible for the control of force, human emotions, mental state, and state of concentration, respectively [2]. Human physiological signals and cognitive analysis research were discovered in the 1920s by German neurologist, named Berger, starting research on human brainwaves [3]. After decades of research, the results showed that measurement analysis of the brainwaves can show whether or not human's mental/cognitive status is in a sober state [3]. In the recent year, the speed of the computer signal processing technology increased until it could sufficiently process the complex brainwave signals measured in real-time. Information about the mental status thus gradually revealed a research in information science called affective computing [2-3].

Electroencephalography (EEG) is traditionally used to measure the brainwaves. Each type of brainwave is associated with one's state of consciousness and different mood state [4-7]. Different neural activities will produce different brainwave patterns, thus demonstrating a different brain state. Different brainwave patterns make brainwaves of different amplitude and frequency. Beta waves, which are brainwaves between 12 to 30 $\mathrm{Hz}$, mean the brain is in a focused state. Alpha waves, which are brainwaves between 8 to $12 \mathrm{~Hz}$, mean the brain is in a calm, relaxed state. From all types of brainwave, beta brainwave is seen in normal activities as well as stressful conditions or difficulties in mental concentration. On the other hand alpha wave is seen in wakefulness, relaxed, effortless and alertness condition. Therefore, persons with high alpha wave and low in beta wave could indicate status of relaxation, arousal, less stress and better concentration [8-12].

The way we focus on specific task can cause a measurable shock to brainwaves which is recorded by EEG [13]. Previous studies reported that different forms of focus could form different brainwave frequencies which are usually recorded in the range of 1 to $50 \mathrm{~Hz}$. The aim of this study thus was to explore the modifications of EEG activities and brainwave cloud classroom training program in elderly. The integration of these neurophysiological parameters may contribute to the understanding of EEG correlates of brain training conditions. In order to detect modifications of EEG frequencies, we used the lightweight EEG device, MindWave Mobile, NeuroSky, Inc. for EEG activity recordings. 


\section{MATERIALS AND MEDTHODS}

\section{A. Participants}

This study was done with fourteen participants, aged

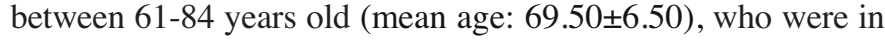
good health, no congenital illness, no record of brain surgery, not taking medicines or drugs that affect to nervous system. Exclusion criteria included left handedness; history of medical and neurologic diseases; binge eating disorders and other psychiatric disorders; head trauma; assumption of Central Nervous System active drugs in the two weeks prior to study entry; and presence of EEG abnormalities at the baseline recording. After receiving information about the aims of the study, all participants provided written consent to participate in the study that was performed according to the Helsinki declaration standards and was approved by the local institutional review board of Mae Fah Luang University, Thailand.

\section{B. Tools and Equipments}

Personal information of all participants including age, gender, nationality, and history of illness were recorded before starting the study. In this study, the electroencephalography (EEG) was applied in order to record the brainwaves of all participants. The effectiveness of commercially available lightweight EEG devices, NeuroSky's Mindwave Mobile, was used in this study. The neuroheadset, NeuroSky's Mindwave Mobile, was used to display the output, analyze and record EEG activity. The principles of analytical check were based on the 1020 system or International 10-20 system by displaying the EEG output. Mindwave Mobile provided two 100-state outputs operating at $1 \mathrm{~Hz}$ via the application of a single electrode and signal-processing unit in a headband arrangement. The principle advantage of the Mindwave Mobile was its unobtrusive nature, which minimizes the aforementioned difficulties in conducting accurate user studies. However, the Mindwave Mobile provided a much coarser picture of brain activity than multi-electrode EEG or other technologies (see Figure 1). According to the lightweight EEG device, NeuroSky's Mindwave Mobile, EEG frequency analysis was performed by means of a Fast Fourier Transform (FFT) algorithm, with a 2-second interval on the EEG signal. The following frequency bands were considered: delta $(0.1-3.0 \mathrm{~Hz})$; theta $(4.0-7.0 \mathrm{~Hz})$; alpha $(8.0-13.0 \mathrm{~Hz})$; beta $(14.0-30.0 \mathrm{~Hz})$; and gamma $(31.0-60.0 \mathrm{~Hz})$.
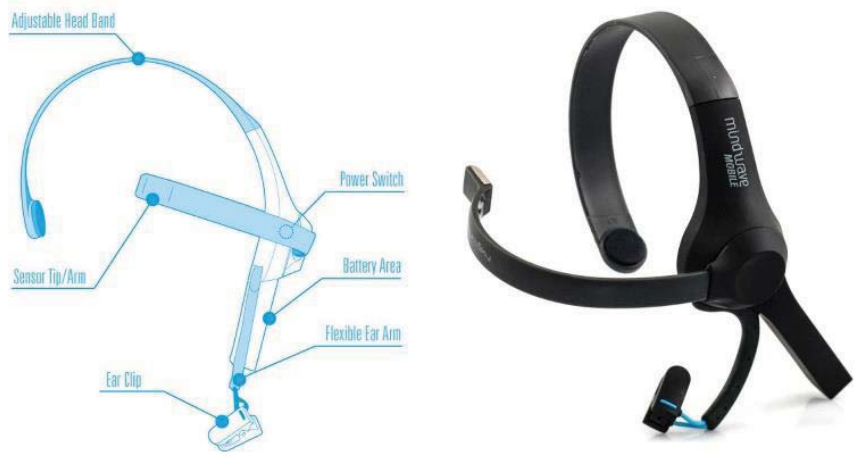

Figure 1. Mindwave mobile electroencephalography device (NeuroSky Inc.)
In 2009, NeuroSky released the first Brain- Computer Interfaces (BCI) control. Neurosky MindSet is different from the past $\mathrm{BCI}$ devices. It is a single EEG channel comparing with the traditional multi-channels EEG technology and makes wearing easier and more comfortable with no need of people to help you wear it. The NeuroSky product uses its patented ThinkGear chip that can filter out the noise from the EEG to get eSense [14].

For brainwave cloud classroom training program, brainwave attention lesson was divided into four different core parts. Every part had a plurality of small chapters as follows:

First Part - Meditation Practice: This part aimed to teach the brain the relaxation method by making it recognized and remembered the state of relaxation through exercises and meditation.

Second Part - Left and Right Brain Harmony: This section aimed to obtain the best results of brain development in a relaxed state by harmonizing both sides of the brain through different left and right brain exercise.

Third Part - Listening, Speaking and Writing Exercises: This section aimed to train participants' listening, speaking and writing skills, so that participants could maximize while doing these things in a relaxed state. This was an important skill enhancement exercise.

Fourth Part - Thinking Exercise: This section aimed to train participants to be able to seriously ponder problems, and at the same time meaningfully and effectively solve them while being in a comfortable, open, and relaxed state (see Figure 2).

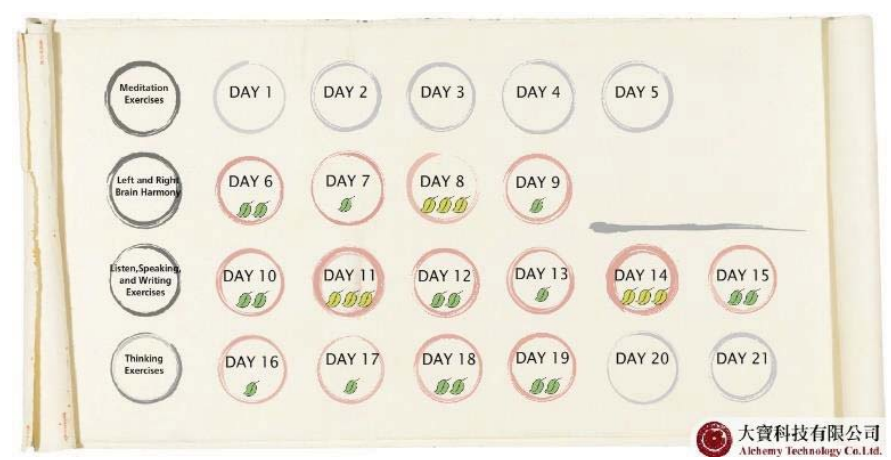

Figure 2. Brainwave Cloud Classroom Program with four major core parts.

Finally, a single-channel EEG was designed to collect brain activity data from the participants' brain. Simplicity and efficiency were the main reasons for designing a single-channel EEG monitoring system.

\section{Statistical analysis}

All demographic data of participants were analyzed by using descriptive analysis. The qualitative data was summarized in term of frequency and percentage whereas the quantitative data was summarized in term of average and standard deviation. Each type of EEG activities was compared by using inferential statistic, $t$-test. Every tests were set to the statistic significant at $p<0.05$. 


\section{RESULT}

TABLE I. COMPARASION OF BRAINWAVES BETWEEN BEFORE AND AFTER BRAINWAVE CLOUD CLASSROOM BRAIN TRAINING

\begin{tabular}{|c|c|c|c|c|c|c|}
\hline \multirow{2}{*}{$\begin{array}{c}\text { Brain } \\
\text { waves }\end{array}$} & \multicolumn{2}{|c|}{ Before Training } & \multicolumn{2}{|c|}{ After Training } & \multirow{2}{*}{$\begin{array}{c}\text { Paired } \\
\text { t-test }\end{array}$} & $p$-value \\
\cline { 2 - 5 } & Mean & SD & Mean & SD & \\
\hline Delta & 0.018 & 0.062 & 0.016 & 0.026 & 0.78 & 0.41 \\
\hline Theta & 0.017 & 0.024 & 0.014 & 0.071 & 1.23 & 0.21 \\
\hline Alpha & 0.009 & 0.031 & 0.003 & 0.023 & 0.97 & 0.45 \\
\hline Beta & 0.008 & 0.016 & 0.003 & 0.010 & 1.16 & 0.27 \\
\hline Gamma & 0.001 & 0.026 & 0.001 & 0.032 & 1.12 & 0.29 \\
\hline
\end{tabular}

Based on Table I, it was found that delta, theta, alpha and beta brainwaves gradually decreased with no statistically significant while gamma brainwave did not change. On the other hand, gamma brainwave was found to be sustained while performing the brainwave cloud classroom task.

TABLE II. DELTA BRAINWAVE CHANGES BETWEEN BEFORE AND AFTER BRAINWAVE CLOUD CLASSROOM BRAIN TRAINING

\begin{tabular}{|c|c|c|c|c|c|c|}
\hline \multirow{2}{*}{$\begin{array}{l}\text { Brain } \\
\text { wave }\end{array}$} & \multicolumn{2}{|c|}{ Before Training } & \multicolumn{2}{|c|}{ After Training } & \multirow{2}{*}{$\begin{array}{c}\text { Paired } \\
\text { t-test }\end{array}$} & \multirow[t]{2}{*}{$p$-value } \\
\hline & Mean & SD & Mean & SD & & \\
\hline Delta & 0.018 & 0.062 & 0.016 & 0.026 & 0.78 & 0.41 \\
\hline
\end{tabular}

According to Table II, it was found that delta brainwave was gradually decreased with no statistically significant while performing the task compared to baseline (before training: $0.018 \pm 0.062 \mu \mathrm{V}$; after training: $0.016 \pm 0.026 \mu \mathrm{V} ; \mathrm{t}(13)=0.78$; $p=0.41)$.

TABLE III. THETA BRAINWAVE CHANGES BETWEEN BEFORE AND AFTER BRAINWAVE CLOUD CLASSROOM BRAIN TRAINING

\begin{tabular}{|c|c|c|c|c|c|c|}
\hline \multirow{2}{*}{$\begin{array}{c}\text { Brain } \\
\text { waves }\end{array}$} & \multicolumn{2}{|c|}{ Before Training } & \multicolumn{2}{|c|}{ After Training } & \multirow{2}{*}{$\begin{array}{c}\text { Paired } \\
\text { t-test }\end{array}$} & $p$-value \\
\cline { 2 - 5 } & Mean & SD & Mean & SD & \\
\hline Theta & 0.017 & 0.024 & 0.014 & 0.071 & 1.23 & 0.21 \\
\hline
\end{tabular}

According to Table III, it was found that theta brainwave was gradually decreased with no statistically significant while performing the task compared to baseline (before training: $0.017 \pm 0.024 \mu \mathrm{V}$; after training: $0.014 \pm 0.071 \mu \mathrm{V} ; \mathrm{t}(13)=1.23$; $p=0.21)$.

TABLE IV. ALPHA BRAINWAVE CHANGES BETWEEN BEFORE AND AFTER BRAINWAVE CLOUD CLASSROOM BRAIN TRAINING

\begin{tabular}{|c|c|c|c|c|c|c|}
\hline \multirow{2}{*}{$\begin{array}{c}\text { Brain } \\
\text { waves }\end{array}$} & \multicolumn{2}{|c|}{ Before Training } & \multicolumn{2}{|c|}{ After Training } & Paired & $p$-value \\
\cline { 2 - 5 } & Mean & SD & Mean & SD & & \\
\hline Alpha & 0.009 & 0.031 & 0.003 & 0.023 & 0.97 & 0.45 \\
\hline
\end{tabular}

Similarly, it was found that alpha brainwave was gradually decreased with no statistically significant while performing the task compared to baseline (before training: $0.009 \pm 0.031 \mu \mathrm{V}$; after training: $1.003 \pm 0.023 \mu \mathrm{V} ; \mathrm{t}(13)=0.97 ; p=0.45$ ) (Table IV).
TABLE V. BETA BRAINWAVE CHANGES BETWEEN BEFORE AND AFTER BRAINWAVE CLOUD CLASSROOM BRAIN TRAINING

\begin{tabular}{|c|c|c|c|c|c|c|}
\hline \multirow{2}{*}{$\begin{array}{c}\text { Brain } \\
\text { waves }\end{array}$} & \multicolumn{2}{|c|}{ Before Training } & \multicolumn{2}{|c|}{ After Training } & \multirow{2}{*}{$\begin{array}{c}\text { Paired } \\
\text { t-test }\end{array}$} & $p$-value \\
\cline { 2 - 5 } & Mean & SD & Mean & SD & \\
\hline Beta & 0.008 & 0.016 & 0.003 & 0.010 & 1.16 & 0.27 \\
\hline
\end{tabular}

According to Table V, it was found that beta brainwave was gradually decreased with no statistically significant while performing the task compared to baseline (before training: $0.008 \pm 0.016 \mu \mathrm{V}$; after training: $0.003 \pm 0.010 \mu \mathrm{V} ; \mathrm{t}(13)=1.16$; $p=0.27$ ) (Table VI).

TABLE VI. GAMMA BRAINWAVE CHANGES BETWEEN BEFORE AND AFTER BRAINWAVE CLOUD CLASSROOM BRAIN TRAINING

\begin{tabular}{|c|c|c|c|c|c|c|}
\hline \multirow{2}{*}{$\begin{array}{c}\text { Brain } \\
\text { waves }\end{array}$} & \multicolumn{2}{|c|}{ Before Training } & \multicolumn{2}{|c|}{ After Training } & \multirow{2}{*}{$\begin{array}{c}\text { Paired } \\
\text { t-test }\end{array}$} & $p$-value \\
\cline { 2 - 5 } & Mean & SD & Mean & SD & \\
\hline Gamma & 0.001 & 0.026 & 0.001 & 0.032 & 1.12 & 0.29 \\
\hline
\end{tabular}

Finally, it was found that gamma brainwave was gradually decreased with no statistically significant while performing the task compared to baseline (before training: $0.001 \pm 0.026 \mu \mathrm{V}$; after training: $0.001 \pm 0.032 \mu \mathrm{V} ; \mathrm{t}(13)=1.12 ; p=0.29)$ (Table $\mathrm{VI})$.

\section{DISCUSSION}

The results revealed that delta, theta, alpha, and beta frequency bands were gradually decreased with no statistically significant while performing the brainwave cloud classroom training program. However, all participants showed significantly mean improvement in speed, memory, attention, and flexibility, respectively. This study is consistent with previous studies found that the sensorimotor rhythm related to attention $[12,15]$. Unfortunately, the decrease of theta and delta frequency bands in this study were not consistent with previous studies mentioned the increase of theta and alpha powers indicated in the frontal areas [16,17]. In addition, previous studies had shown that both theta and alpha oscillations were known to play an important role in different memory processes and in emotion regulation $[17,18]$. However, other studies have indicated that theta and alpha EEG frequencies respond specifically to visual emotional stimulation and to negative emotions, respectively [19].

Since alpha $(8-13 \mathrm{~Hz})$ activity in EEG is known to be associated with relaxation and a lack of active cognitive processes $[20,21]$, initial stages of meditation research focused primarily on alpha brainwave. Several investigators proposed that theta $(4-7 \mathrm{~Hz})$ activity correlates positively with the level of meditation experience [22]. Some previous studies found that theta and low alpha brainwaves both increased significantly as subjects were more concentrated in the meditation task [20-22].

Brain training has been shown to be efficient in many different areas including mathematics and engineering education [23]. A well-known of mathematics and spatial abilities training was based on the Vanderberg and Kuse [23] who developed the Mental Rotation test. After that Hoyek et al. [24] used a computerized version of this Mental Rotation test to train students' spatial abilities. Moreover, brain and spatial 
ability trainings were shown to impact capacities in scientific learning [25].

\section{CONCLUSION}

This study aimed to study the EEG changes during the brainwave cloud classroom program training in elderly. While performing the brainwave cloud classroom program, EEG activity were recorded by using the lightweight EEG device, Mindwave Mobile, NeuroSky, Inc. Some EEG activity including delta, theta, alpha, and beta brainwaves were gradually decreased with no statistically significant while gamma brainwave did not change.

\section{ACKNOWLEDGMENT}

This research was supported by grant no. 611U109005 (2017) from Brain Science and Engineering Innovation Research Unit, Mae Fah Luang University, Thailand. We thank all of the subjects involved in this research as main data provider of this studies.

\section{REFERENCES}

[1] S.P. Bailey, E.E. Hall, A. Folger, and P.C. Miller, "Changes in EEG during graded exercise on a recumbent cycle ergometer," J. Sports Sci. Med., 2008, vol. 7, pp. 505-511.

[2] K.R. Popper, and J.C. Eccles, "The self and its brain: an argument for interactionism." 1977, Berlin: Springer-Verlag Berlin Heidelberg

[3] H. Bergerz, Uber das Elektroenkephalogram des Menschen, In: AfPN, 1929, vol. 87, pp.527-570. Berlin: Springer.

[4] J.J.B. Allen, J.A. Coan, and M. Nazarian, "Issues and assumptions on the road from raw signals to metrics of frontal EEG asymmetry in emotion", Biol. Psychol., 2004, vol. 67, pp. 183-218.

[5] J.B. Crabbe, and R.K. Dishman, "Brain electrocortical activity during and after exercise: A quantitive synthesis", Psychophysiol., 2004, vol. 41, pp. 563-574.

[6] J.M. Davis, and S.P. Bailey, "Possible mechanisms of central nervous system fatigue during exercise”, Med. Sci. Sport Exer., 1997, vol. 29(1), pp. $45-57$.

[7] T. Kakizaki, "Effects of bicycle exercise on occipital EEG amplitude in male students", Industrial Health, 1988, vol. 26, pp. 191-195

[8] W.R. Black, R.J. Lepping, A.S. Bruce, J. N. Powell, J.M. Bruce, L.E. Martin, and W.K. Simmons, "Tonic hyper-connectivity of reward neurocircuitry in obese children", Obesity (Silver Spring), 2014, vol. 22(7), pp. 1590-1593.

[9] I. Garcia-Garcia, M.A. Jurado, M. Garolera, B. Segura, I. Marques-Iturria, R. Pueyo, and C. Junque, "Functional connectivity in obesity during reward processing", NeuroImage, 2012, vol. 66C, pp. 232-239.

[10] J.R. Tregellas, K.P. Wylie, D.C. Rojas, J. Tanabe, J.K. Martin, E. Kronberg, and M.A. Cornier, "Altered default network activity in obesity”, Obesity (Silver Spring), 2011, vol. 19(12), pp. 2316-2321.
[11] L.I. Tammela, A. Paakkonen, L.J. Karhunen, J. Karhu, M.I. Uusitupa, and J.T. Kuikka, "Brain electrical activity during food presentation in obese binge-eating women", Clin. Physiol. Funct. Imaging, 2010, vol. 30(2), pp. 135-140.

[12] M.R. Ford, J.W. Goethe, and D.K. Dekker, "EEG coherence and power in the discrimination of psychiatric disorders and medication effects", Biol. Psychiatry, 1986, vol. 21(12), pp. 1175-1188.

[13] K. Crowley, A. Sliney, I. Pitt, and D. Murphy, "Evaluating a BrainComputer Interface to Categorize Human Emotional Response" IEEE $10^{\text {th }}$ International Conference on Advanced Learning Technologies (ICALT), 2010, pp. 276-278, Sousse: IEEE Press.

[14] NeuroSky, Inc. NeuroSky's eSense ${ }^{\mathrm{TM}}$ meters and detection of mental state. Technical Report, 2009. NeuroSky, Inc.

[15] M. Balconi, "Frontal brain oscillation modulation in facial emotion comprehension. The role of reward and inhibitory systems in subliminal and supraliminal processing", Eur. J. Cog., Psychol., 2011, vol. 23(6), pp. 723-735.

[16] W. Klimesch, P. Sauseng, and S. Hanslmayr, "EEG alpha oscillations: the inhibition-timing hypothesis", Brain Res. Rev., 2007, vol. 53(1), pp. 6388.

[17] F.T. Crews, and C.A. Boettiger, "Impulsivity, frontal lobes and risk for addiction”, Pharmacol. Biochem. Behav., 2009, vol. 93(3), pp. 237-247.

[18] M.A. Parvaz, N. Alia-Klein, P.A. Woicik, N.D. Volkow, and R.Z. Goldstein, "Neuroimaging for drug addiction and related behaviors", Rev. Neurosci., 2011, vol. 22(6), pp. 609-624.

[19] O. Jensen, J. Gelfand, J. Kounios, and J.E. Lisman, "Oscillations in the alpha band $(9-12 \mathrm{~Hz})$ increase with memory load during retention in a short-term memory task", Cereb. Cort., 2002, vol. 12(8), pp. 877-882.

[20] G. Pfurtscheller, A. Jr. Stancak, C. Neuper, "Event-related Synchronization (ERS) in the Alpha Band-an Electrophysiological Correlate of Cortical Idling: A Review, Int. J. Psychophysiol. 1996; 24:39-46.

[21] O. Jensen, A. Mazaheri, "Shaping Functional Architecture by Oscillatory Alpha Activity: Gating by Inhibition." Front. Hum. Neurosci., 2010;4:186

[22] J. Lagopoulos, J. Xu, I. Rasmussen, A. Vik, G.S. Malhi, C.F. Eliassen, I.E. Arntsen, J.G. Sother, S. Hollup, A. Holen, S. Davanger, O. Ellingsen, "Increased Theta and Alpha EEG Activity During Nondirective Meditation." J Altern Complement Med., 2009; 15(11):1187-1192.

[23] N. Hoyek, C. Collet, O. Rastello, P. Fargier, P. Thiriet, and A. Guillot, "Enhancement of mental rotation abilities and its effect on anatomy learning," Teaching and Learning Med., 2009, vol. 21, pp. 201-06.

[24] A. J. Bishop, "Spatial abilities and mathematics education - a review," Edu. Studies Math., 1980, vol. 11, pp. 257-69.

[25] A. Vromen, J. A. Verbunt, S. Rasquin, and D. T. Wade, "Motor imagery in patients with a right hemisphere stroke and unilateral neglect," Brain Injury, 2011, vol. 25, pp. 387-93. 